\title{
Impact of indirect evaporative air cooler type on the performance of desiccant systems
}

\author{
Anna Pacak $^{1, *}$, Aleksandra Cichoń $^{1}$, Demis Pandelidis ${ }^{1}$, and Sergey Anisimov ${ }^{1}$ \\ ${ }^{1}$ Wrocław University of Science and Technology, Faculty of Environmental Engineering, Department \\ of Air Conditioning, Heating, Gas Engineering and Air Protection, 4/6 Norwida st., 50-373 \\ Wroclaw, Poland
}

\begin{abstract}
In this study, two different indirect evaporative coolers operating with a desiccant wheel are compared theoretically: System A with the regenerative Maisotsenko Cycle (M-Cycle) unit and System B with the cross-flow M-cycle unit. Each system component performance was simulated using the original $\varepsilon$-NTU model. The influence of selected operational factors, such as inlet air temperature, humidity and regeneration air temperature for two system configurations was analysed and compared. It was established, that System B obtains higher cooling capacities and is more sensitive on ambient air humidity changes than System A.
\end{abstract}

\section{Introduction}

Cooling energy plays a crucial role in energy demand in buildings because of indoor air quality increasing requirements. The reports show that buildings consume about $20 \%$ to $40 \%$ of total energy use in developed countries. Depending on the country space air conditioning uses from $42 \%$ in Spain to $62 \%$ in UK of total energy usage in residential sector. [1]. Vapor-compression systems dominate as a way to produce the cooling energy but they have a main disadvantage. These systems consume an electrical energy to achieve the appropriate indoor air parameters. That is why the operational costs of such systems are comparatively high [2]. It is possible to replace them by the environmental friendly, alternative cooling methods. One of such solutions, which is considered as the most promising for moderate and humid climates, is a desiccant cooling system [3]. It is based on the combination of desiccant unit (solid or liquid) and an indirect evaporative cooling device. In this solution, the air is firstly dehumidified and after that, it is cooled to the appropriate temperature level without adding any moisture in an indirect evaporative air cooler. It should be underlined, that each desiccant air-conditioning system needs the energy for desiccant wheel regeneration, which can be tapped from solar collectors, heat pump or waste energy. This fact makes desiccant system a promising solution, and that is why it has been deeply studied by many authors for recent years. Rajat Subhra Das and Sanjeev Jain [4] presented the performance of a small capacity liquid desiccant evaporative cooling system for small office application in terms of its dehumidification effectiveness,

\footnotetext{
*Corresponding author: anna.pacak@pwr.edu.pl
} 
moisture removal rate, cooling capacity and thermal COP. Jinzhe Nie et al. [5] developed new desiccant cooling system cooperating with the heat pump (HP-SDC). This system was compared to the conventional ventilation system. The results show that HP-SDC system performance was higher. Chen et. al. [3] proposed also a liquid desiccant dehumidifier (LDD-RIEC) and regenerative indirect evaporative cooling system for ventilation purposes. The energy for regeneration was tapped from solar collectors. The optimal extraction air ratio equal to 0.3 was established considering the influence of system components parameters. The energy saving ratio of proposed system comparing to conventional $\mathrm{A} / \mathrm{C}$ system ranges from $22.4 \%$ to $53.2 \%$. M. Kashif Shahzad [6] presented the experimental investigation of desiccant solid system with M-Cycle cross flow heat exchanger (MC-DAC) performance. The results indicate that with providing the same supply airflow MC-DAC system was around 60-65\% more efficient than typical Desiccant Air Conditioning System (DAC). What is important, the desiccant wheel was regenerated by low temperature airflow.

Currently, Maisotsenko-cycle (M-Cycle) units are treated as the most effective indirect evaporative cooling devices [7]. That is why in this study two M-Cycle evaporative heat exchangers operating with a desiccant wheel are compared: regenerative M-Cycle heat exchanger and cross-flow heat exchanger to establish which one allows the system to obtain higher performance.

\section{Proposed systems description}

The operation principal of desiccant systems is based on decreasing of airflow moisture content, which allows for more effective evaporative cooling. As a result, supply air temperature is lower [8].There is a special advantage of using indirect evaporative heat exchangers instead of direct ones in such systems. In the case of conventional desiccant cooling system, the end-point air treatment is connected with airflow humidification in direct evaporative coolers. In the case of indirect evaporative heat exchangers, the same required parameters of the supply air can be reached, but, taking into account, that air is cooled sensibly (without moisture content rising) a significantly lower air dehumidification is required in the desiccant wheel. It is the main premise to develop desiccant systems based on the M-Cycle indirect evaporative coolers. To implement this solution effectively, a proper device needs be chosen. In this regard, two selected desiccant systems integrated with different M-Cycle heat exchangers were compared in this study.

Table 1. Main system components operating characteristics [9].

\begin{tabular}{|lr|lc|}
\hline \multicolumn{2}{|l|}{ Indirect evaporative air coolers parameters } & Desiccant wheel parameters & 750 \\
Length, m & 0.5 & Specific heat capacity (silica gel), J/(kg K) & Sinusoidal \\
Width, m & 0.5 & Channel type & 1.24 \\
Height, m & 0.5 & Channel height, mm & 2.21 \\
Channel height, mm & 3.0 & Channel width, mm & 0.30 \\
Channel width, mm & 25 & Wall thickness, mm & 0.1 \\
Working to intake air ratio (cross-flow & 1.0 & Channel length, m & 0.5 \\
M-Cycle HMX and crossflow HMX) & & & 30 \\
Working to intake air ratio & 0.3 & Wheel diameter, m & 8 \\
(regenerative M-Cycle HMX) & & Percent of wheel used for regeneration & \\
Length, m & 0.5 & airflow, \% & \\
Width, m & 0.5 & Rotational speed, cycles/hour & \\
\hline
\end{tabular}

The first of analysed desiccant air-conditioning system (System A) is equipped with the high performance regenerative heat exchanger, which is characterised by its simple construction (see. Fig. 1(a)). It should be underlined, that this device needs a specific 
working to primary airflow ratio to be assumed. In previous publications authors found out, that this ratio should be kept between 0.3 and 0.45 [10]. In this study, the working to primary airflow ratio 0.3 is chosen to maximize the supply airflow. The second system (System B) consists of desiccant wheel and a cross-flow M-Cycle heat exchanger (see. Fig. 1(b)). Because of characteristic construction of this unit, the working to primary airflow ratio is equal to 1 . Complete set of system components characteristic parameters are presented in Table 1. Moreover, desiccant wheels in both systems are regenerated with the same airflow rate.

(a)

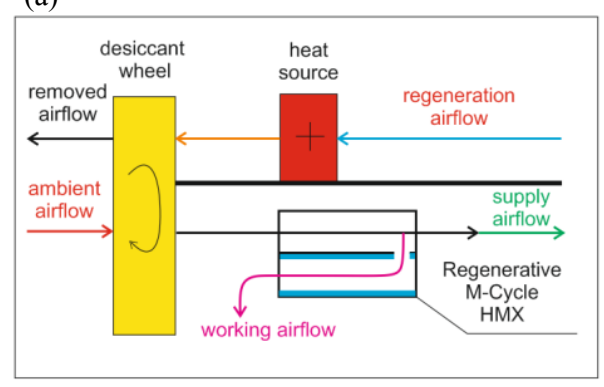

(b)

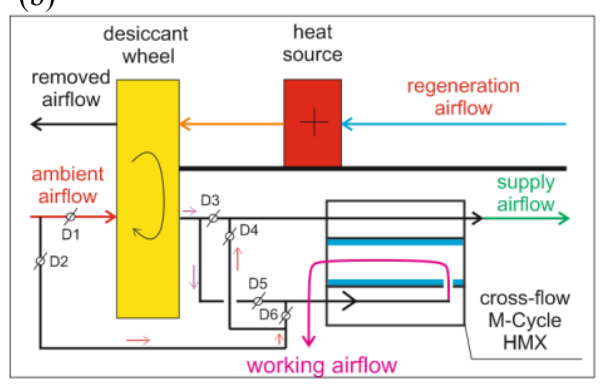

Fig. 1. Analysed systems schemes (a) System A with counter-flow regenerative heat exchanger.

(b) System B with M-Cycle cross-flow heat exchanger.

Due to the ambient air temperature changes during entire cooling season System B runs in three operation modes for which dampers positioning is presented in Table 2. In case of dry ambient air the System B runs in the first mode and desiccant wheel is bypassed by entire airflow (primary and working airflow). When ambient air is dry enough to provide proper indoor air conditions but not dry enough to realize evaporative cooling process effectively, System B runs in mode 2. In this case, the working airflow is dehumidified and primary airflow is by-passed. When outdoor air is too humid mode 3, is applied and entire airflow is dehumidified in the desiccant wheel.

Table 2. System B operational modes.

\begin{tabular}{|c|c|c|c|c|c|c|}
\hline & D1 & D2 & D3 & D4 & D5 & D6 \\
\hline Mode 1 & closed & open & closed & open & closed & open \\
\hline Mode 2 & $50 \%$ open & $50 \%$ open & closed & open & open & closed \\
\hline Mode 3 & open & closed & open & closed & open & closed \\
\hline
\end{tabular}

Such configuration allows for maximum energy savings. However, this system is sensitive to outdoor air humidity changes: there is always a risk that in rapidly changing weather conditions, the air in the conditioned spaces might be too humid.

\section{Methods}

M-Cycle regenerative air cooler, cross-flow M-cycle air cooler and desiccant wheel were simulated using original $\varepsilon$-NTU models. These models are created with an assumption that the airflow is treated as gaseous fluid, which has temperature, velocity and mass transfer potential equalled to bulk average values in sections normal to the plate surface of heat exchanger. Models equations, validation of these models are presented in author's previous works $[8,9,11]$. 


\section{Comparison under the same supply airflow rate}

In this section, the comparison of the selected systems with the assumption that they deliver the same airflow rate to the occupants is presented. Due to this fact, there is a difference between values of input airflows delivered to the desiccant wheel in System A and Systems B. (430 and $300 \mathrm{~m}^{3} / \mathrm{h}$ respectively). The regeneration airflow value in this case is equal to $100 \mathrm{~m}^{3} / \mathrm{h}$. The simulation results are presented in Figs. 2 and 3. The lowest outlet supply air temperatures and highest cooling capacity are obtained in System B with the cross-flow M-Cycle HMX implemented. The fact that System A obtains lower effectiveness is theoretically surprising result, due to the fact that it was established in many recent studies that counter-flow regenerative unit obtains higher temperature effectiveness than the cross-flow M-Cycle unit and a significantly higher effectiveness than the cross-flow heat exchanger [12].
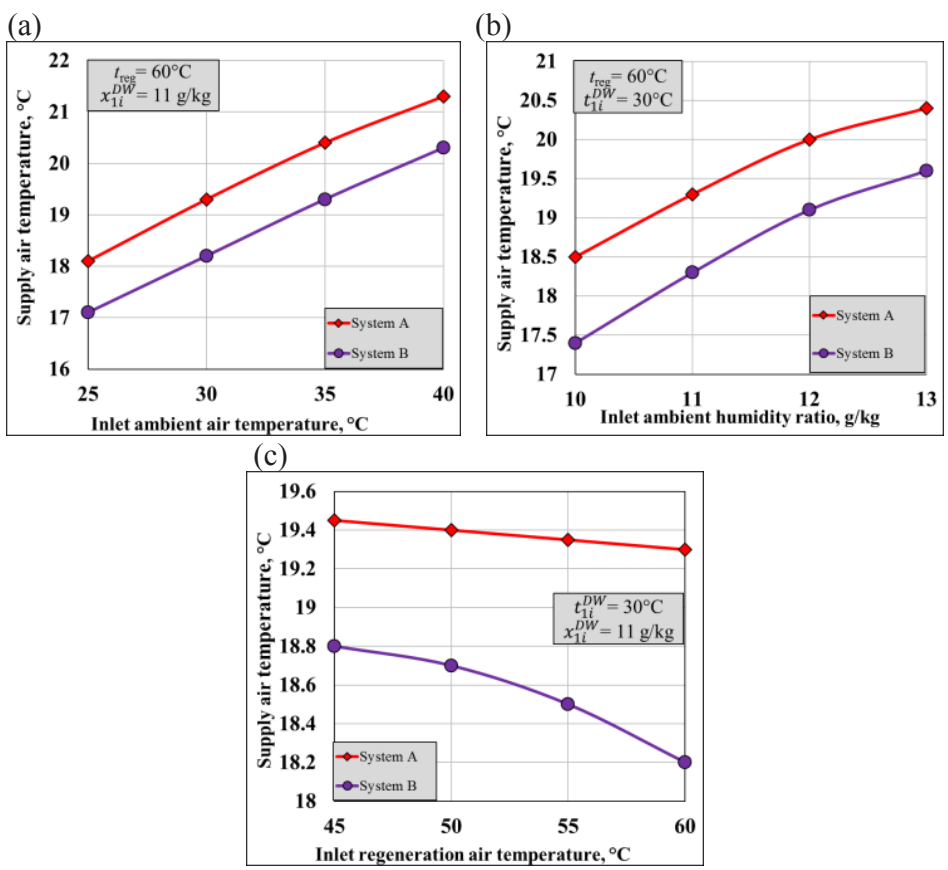

Fig. 2. Obtained supply air temperatures under the same supply airflow rate. (a) For variable inlet temperature (b) For variable inlet humidity ratio. (c) For variable regeneration air temperature.

In the analysed case, the regenerative unit operates in less beneficial configuration than the cross-flow unit does. In order to deliver the airflow equal $300 \mathrm{~m}^{3} / \mathrm{h}$ to the conditioned space, System B requires the dehumidification of the same airflow rate with the desiccant wheel. The System A needs higher airflow rate which has to be dehumidified before it is treated in counter-flow heat exchanger, to provide the same airflow rate as System B does. It is because of the fact that the part of the cooled product airflow is reversed to the wet channel (see Fig. 1(a)). The higher airflow rate also results in the higher airflow velocity in the dry channels of the regenerative HMX.

It should be underlined that in case of System B, the cross-flow unit operates on two different airflows. Basically, the ambient air is delivered to the primary channels, and dehumidified air is delivered to the working air channels. These airflows may be divided like that because the primary air requires dehumidification only in the case when indoor 
latent heat loads need to be assimilated. The higher inlet airflow rate in System A results in less effective dehumidification process and, consequently, less effective evaporative cooling process is observed. As mentioned above, the higher airflow rate results in the NTU value decrement in the regenerative exchanger and hence less effective heat transfer is noticed.

(a)

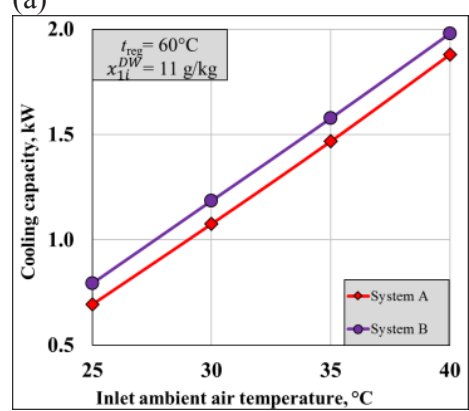

(c) (b)

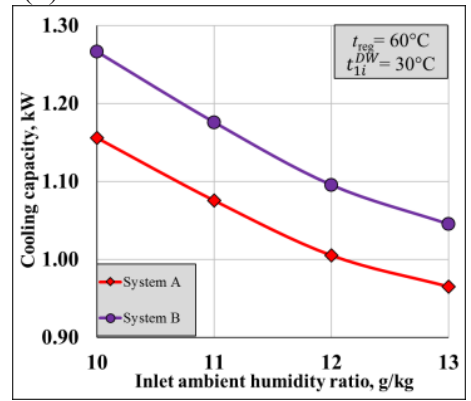

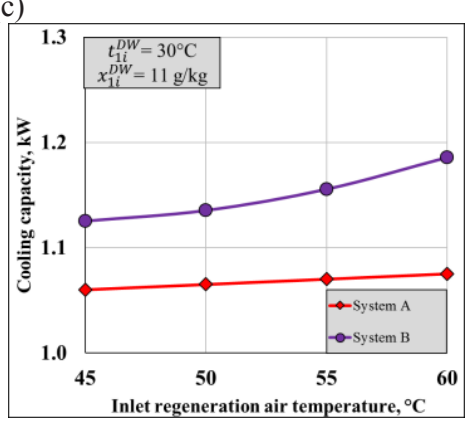

Fig. 3. Obtained cooling capacities under the same supply airflow rate. (a) For variable inlet temperature (b) For variable inlet humidity ratio. (c) For variable regeneration air temperature.

The system with the cross-flow M-Cycle (System B) exchanger has the significant advantage over System A, the working to intake air ratio is equal to 1 and the NTU in the primary air channels is higher. The additional advantage is that the airflow at the entrance to the primary air channels is colder than in case of the System A, because the desiccant wheel is bypassed (mode 2). That is why lower outlet temperatures can be achieved. On the other hand, the total temperature drop on the regenerative exchanger is higher (i.e., about $20^{\circ} \mathrm{C}$ to $12^{\circ} \mathrm{C}$ ). Because of the higher airflow temperature at the entrance to the regenerative air cooler, the significant temperature drop does not result in low outlet temperatures. Both systems for ambient air humidity ratio increment achieve higher supply air temperature (Fig. 2(b)) and lower cooling capacities Fig. 3(b). The comparison under variable regeneration air temperature is presented in Fig. 2(c) and Fig. 3(c). It can be seen, that regeneration air temperature affects System B more than System A. Moreover, the systems effectiveness increases with the enhancement of regeneration air temperature. This follows from the fact that regeneration airflow with higher temperature removes the moisture from the desiccant wheel core and more moisture can be removed from the processed airflow. Nevertheless, it is related to higher temperature of the airflow after before the evaporative coolers as well. The M-Cycle heat exchangers in System $\mathrm{A}$ and $\mathrm{B}$ are generally effective, even when incoming air is not highly dehumidified because obtained temperatures are comparatively low. 


\section{Comparison under the same dehumidified airflow rate}

Systems performance is also analysed with the assumption that rotor dehumidifier treats the same value of the air stream. It means that both systems deliver different value of the supply airflow to the occupants which is equal to $300 \mathrm{~m}^{3} / \mathrm{h}$ (System A) and $430 \mathrm{~m}^{3} / \mathrm{h}$ (System B). The regeneration airflow value is $100 \mathrm{~m}^{3} / \mathrm{h}$ as it is assumed in comparison presented in previous section.

(a)

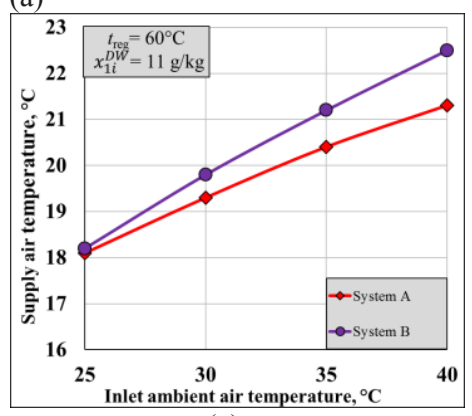

(b)

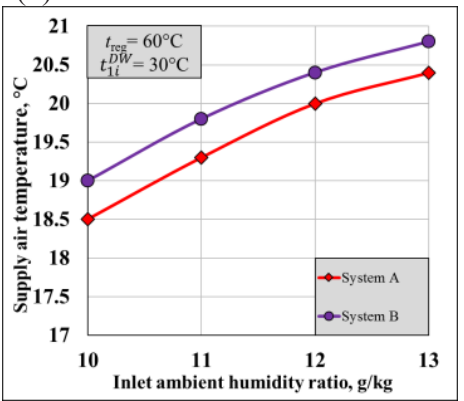

(c)

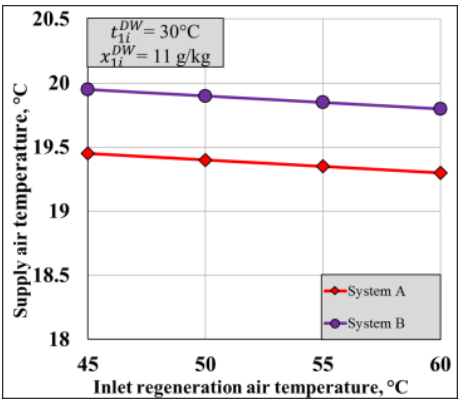

Fig. 4. Obtained supply temperatures under the same dehumidified airflow rate. (a) For variable inlet temperature (b) For variable inlet humidity ratio. (c) For variable regeneration air temperature.

The results of simulations under the same conditions are presented in Fig. 4 and Fig. 5. In this configuration System A obtains lower supply temperatures, the difference is about $1{ }^{\circ} \mathrm{C}$. On the other hand System B has significantly more favourable cooling capacity than System A does (see Fig 5). It is because of the fact that cross-flow heat exchanger operates on higher airflow rate. It is worth to underlined, that System B can provide higher cooling capacity by using the same amount of energy for the desiccant wheel regeneration. Due to the fact, that System A delivers colder air to the primary air channels, it consumes less water for the evaporation.

The summary percentage cooling capacity advantage of System B over System A is presented in Table 3. As one can see, under the same dehumidified airflow rate, the performance of System B is even 33\% higher than System A. The smallest difference (6.2\%) is observed when AHU treats the same supply airflow and the regeneration temperature is equal to $45^{\circ} \mathrm{C}$. 
(a)

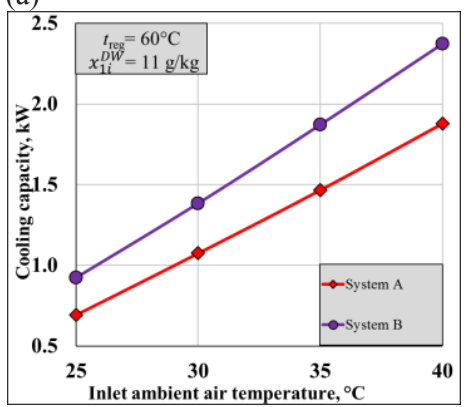

(b)

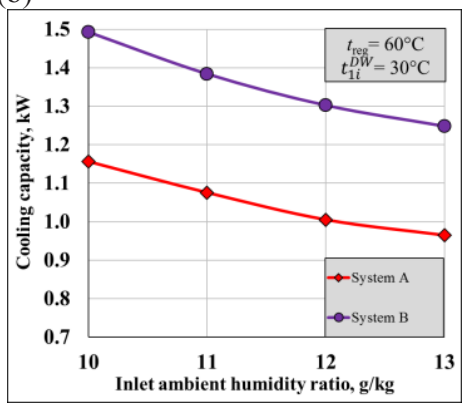

(c)

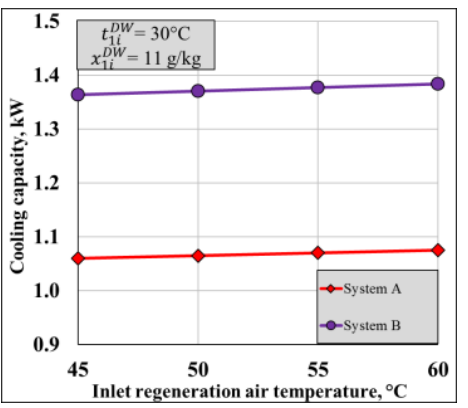

Fig. 5. Obtained cooling capacities under the same dehumidified airflow rate. (a) For variable inlet temperature (b) For variable inlet humidity ratio. (c) For variable regeneration air temperature.

Table 3. The cooling capacity advantage of System B over System A (in \%).

\begin{tabular}{|c|c|c|c|c|c|c|c|}
\hline \multicolumn{3}{|c|}{ under the same supply airflow rate } & \multicolumn{4}{c|}{ under the same dehumidified airflow rate } \\
\hline \multicolumn{3}{|c|}{ inlet ambient air temperature, ${ }^{\circ} \mathbf{C}$} & \multicolumn{4}{c|}{ inlet ambient air temperature, ${ }^{\circ} \mathbf{C}$} \\
\hline $\mathbf{2 5}$ & $\mathbf{3 0}$ & $\mathbf{3 5}$ & $\mathbf{4 0}$ & $\mathbf{2 5}$ & $\mathbf{3 0}$ & $\mathbf{3 5}$ & $\mathbf{4 0}$ \\
\hline $14.5 \%$ & $10.3 \%$ & $7.5 \%$ & $5.3 \%$ & $33.0 \%$ & $28.7 \%$ & $27.6 \%$ & $26.3 \%$ \\
\hline \multicolumn{3}{|c|}{ inlet ambient air humidity, g/kg } & \multicolumn{4}{|c|}{ inlet ambient air humidity, g/kg } \\
\hline $\mathbf{1 0 . 0}$ & $\mathbf{1 1 . 0}$ & $\mathbf{1 2 . 0}$ & $\mathbf{1 3 . 0}$ & $\mathbf{1 0 . 0}$ & $\mathbf{1 1 . 0}$ & $\mathbf{1 2 . 0}$ & $\mathbf{1 3 . 0}$ \\
\hline $9.6 \%$ & $9.3 \%$ & $9.0 \%$ & $8.3 \%$ & $29.1 \%$ & $28.7 \%$ & $29.6 \%$ & $29.4 \%$ \\
\hline \multicolumn{6}{|c|}{ inlet regeneration air temperature, ${ }^{\circ} \mathbf{C}$} & \multicolumn{2}{c|}{ inlet regeneration air temperature, ${ }^{\circ} \mathbf{C}$} \\
\hline $\mathbf{4 5 . 0}$ & $\mathbf{5 0 . 0}$ & $\mathbf{5 5 . 0}$ & $\mathbf{6 0 . 0}$ & $\mathbf{4 5 . 0}$ & $\mathbf{5 0 . 0}$ & $\mathbf{5 5 . 0}$ & $\mathbf{6 0 . 0}$ \\
\hline $6.2 \%$ & $6.6 \%$ & $8.0 \%$ & $10.3 \%$ & $28.6 \%$ & $28.6 \%$ & $28.7 \%$ & $28.7 \%$ \\
\hline
\end{tabular}

\section{Conclusions}

This paper presents a performance comparison of two selected desiccant systems equipped with different evaporative air coolers: the regenerative M-Cycle and the cross flow Maisotsenko cycle heat and mass exchanger. It is important fact that each of presented solutions required a different system arrangement. It has a great influence on the effectiveness of desiccant systems, which was proved by obtained supply temperature and cooling capacity presentation. Systems were compared under different operational conditions with two main assumptions: that the same airflow rate is dehumidified and the same supply airflow rate is delivered.

The results of the conducted investigations are summarized as follows:

- System B with cross-flow M-Cycle HMX show higher sensitivity to ambient air humidity changes than System A. 
- The system with the cross-flow M-Cycle unit (System B) allows to obtain lower supply air temperatures and larger cooling capacities. It is an elastic solution: the ambient air may or may not be delivered to the desiccant wheel before it is directed to the primary air channels, which allows to keep comfortable conditions in the conditioned space.

- System B has more complicated construction than System A.

- The regeneration air temperature affects System B more than System A with the assumption that the same supply airflow rate is delivered to the occupants.

- Under the comparison with the same dehumidified airflow rate System A obtains lower supply air temperatures. On the other hand, System B achieves higher cooling capacities.

It is important to mention, that application of one of the analysed systems needs to be preceded by a very detail economic analysis. Depending on the type of the object, energy prices and other important conditions, each of the studied systems may be the most effective solution.

One of the co-authors, Demis Pandelidis, received financial support for his research from resources for scientific work for years 2016-2019 from Polish Ministry of Science and High Education (program "Iuventus Plus"), project number IP2015 058274.

\section{Nomenclature}

$t$ - temperature, ${ }^{\circ} \mathrm{C} ; x$ - humidity ratio, $\mathrm{g} / \mathrm{kg}$;

Subscripts: 1 - outdoor airflow; $i$ - inlet; reg - regeneration.

Acronyms: NTU - Number of Transfer Units; DW - desiccant wheel, HMX - heat and mass exchanger.

\section{References}

1. L. Pérez-Lombard, J. Ortiz, C. Pout, Energ. Buildings 40, 394-398 (2008)

2. A. De Angelis, O. Saro, M. Truant, Enrgy Proced. 126, 313-320 (201709)

3. Y. Chen, H. Yang, Y. Luo, Energy 143, 114-127 (2018)

4. R. S. Das, S. Jain, Sol. Energy 153, 289-300 (2017)

5. J. Nie, Z. Li, W. Hu, L. Fang, Q. Zhang, Energ. Buildings 153, 31-40 (2017)

6. M. K. Shahzad, G. Q. Chaudhary, M. Ali, N. A. Sheikh, M. S. Khalil, T. U. Rashid, Appl. Therm. Eng. 128, 1476-1487 (2018)

7. S. Anisimov, D. Pandelidis, J. Danielewicz, Energy Convers. Manage. 88, 426-441 (2014)

8. D. Pandelidis, S. Anisimov, W. M. Worek, P. Drąg, Energ. Buildings 123, 136-150 (2016)

9. D. Pandelidis, S. Anisimov, W. M. Worek, P. Drąg, Energy Convers. Manage. 117, 375-392 (2016)

10. D. Pandelidis, S. Anisimov, W. M Worek., Appl. Therm. Eng. 84, 211-24 (2015)

11. D. Pandelidis, S. Anisimov, W. M. Worek, P. Drąg, Energ. Buildings 140, 154-170 (2017)

12. D. Pandelidis, S. Anisimov, Energy Convers. Manage. 90, 62-83 (2015) 